\title{
A biomembrane grown in situ for improved microfluidic microbial fuel cell performance using a pure culture Geobacter sulfurreducens electroactive biofilm
}

Lingling Gong, ${ }^{\mathrm{a}}$ Mehran Abbaszadeh Amirdehi, ${ }^{\mathrm{a}}$ Jayesh M. Sonawane, ${ }^{\mathrm{a}}$ Nan Jia, ${ }^{\mathrm{a}}$ Leon Torres de Oliveira, ${ }^{\mathrm{a}}$ Jesse Greener ${ }^{\mathrm{a}, *}$

Département de chimie, Faculté des sciences et de génie, Université Laval, Québec G1V 0A6, Canada; CHU de Québec,

Centre de recherche, Université Laval, Québec G1L 3L5, Canada; Corresponding author - jesse.greener@chm.ulaval.ca

\begin{abstract}
Microfluidic microbial fuel cells (MFCs) hold great potential to reproduce core functions of bulk MFCs for study and optimization under precise conditions. Unlike most MFC types, those in a microfluidic format typically do not use a membrane to separate anode and cathode compartments, relying instead on the physics of laminar flow to maintain isolation of independent liquid streams. This lowers cost, device complexity, and should reduce internal resistance. However, to avoid solution crossover, which is likely to occur due to inevitable instabilities during long operational times, authors often separate electrodes by distances of several millimeters or more. This reverses benefits on internal resistance, undermining a prime advantage of microfluidic MFCs. This work demonstrates a facile method for the in-situ synthesis of a microscale membrane, supporting sub-milimeter electrode spacing. The
\end{abstract}


membrane added only $68.5 \Omega$ to the cell internal resistance and its synthesis resulted in no measurable changes to $R_{\mathrm{ct}}$ at either electrode. However, the method to grow the membrane after device synthesis greatly reduced complexity in device fabrication. Overall, the reduced electrode spacing that was facilitated by the membrane lowered internal resistance from $25 \mathrm{k} \Omega$ to $10 \mathrm{k} \Omega$ and provide stable operation even under non-ideal flow conditions. Compared to a state-of-the-art membraneless MFC with $6 \mathrm{~mm}$ electrode spacing, the membrane MFC provided approximately $45 \%$ higher power density, $290 \%$ higher current density and 7 times higher acetate conversation efficiency. Membrane-enhanced flow stability also delivered continuous increases to power density with increased flow rate over baseline levels, rising to $30 \%$ higher for flow rate increases of 100 times.

Keywords: Microfluidics, microbial fuel cells, microfabrication, chitosan membrane, power generation

\section{Introduction}

Microbial fuel cells (MFCs) are fascinating alternative energy sources that can remediate waste streams (e.g., municipal water streams), while producing usable energy. ${ }^{1-5}$ A typical MFC consists of anodic and cathodic chambers that are usually separated by an ion-exchange membrane. ${ }^{6,7}$ The membrane prevents anolytes and catholytes from crossing to the opposite chambers while selectively and efficiently transferring certain ions from one compartment to the other in order to support redox reactions and charge balancing. ${ }^{8-10}$ The use of a membrane enables close electrode placement in non-microfluidic MFCs, which can have a significant impact on the internal resistance, thus improving power output. ${ }^{7,9,11-13}$ For example, recently 
a "near zero gap distance" flow-MFC produced very high-power density at around $8.8 \mathrm{~W} \mathrm{~m}^{-2}$ when electrodes were sandwiched between a $106 \mu \mathrm{m}$ anion exchange membrane which selectively transported hydroxide and better mitigated $\mathrm{pH}$ imbalance between the electrodes. ${ }^{8}$ Much effort has been expended in improving the membrane for high performance (ion selectivity and throughput), but for microfluidic MFCs, their role in preventing anolyte/catholyte mixing is considered less critical because mass transport across laminar coflow interfaces is strictly diffusion limited, and therefore slow. However, in practice, anolyte/catholyte solution crossover can arise during long experiments due to pump instabilities or during solution source replacement or other maintenance operation. Even under ideal flow conditions, simulations have shown that electrode spacing of less than $4 \mathrm{~mm}$ can result in more than $10 \%$ of the inlet acetate concentration diffusing to the cathode. ${ }^{14,15}$ Oftenoverlooked, solution crossover may therefore present a major challenge in realizing the potential advantages of microfluidic MFCs, especially in relation to the fabrication devices with closely spaced electrodes.

Membranes in microfluidics have been demonstrated before by sandwiching an ion exchange membrane between two spacers. ${ }^{16}$ But this limits flexibility in channel design and precision offered by microfabrication tools and the approach requires that the membrane be integrated during assembly which can complicate the fabrication process. From a microfabrication perspective, a more elegant approach would be to form the membrane after the device is fabricated. Various approaches to in site membrane formation have been demonstrated at the interface between two coflowing reagents streams. In one example, nylon polymer membranes were formed by a polycondensation reaction using an adipoyl chloride in 1,2-dichloroethane and hexamethylenediamine in $0.1 \mathrm{M} \mathrm{NaOH}$ solution. ${ }^{17}$ In another, freestanding, semipermeable membranes from the biopolymer chitosan was achieved by precipitation following a switch in molecular polarity at the co-flow interface with a basic solution. ${ }^{18}$ This technique 
has subsequently proliferated in the literature as recently reviewed. ${ }^{19}$ For example, we previously developed microfluidic methods for creating pure and hybrid chitosan membranes with accurate control over their dimensions. ${ }^{20,21}$ In this study we explore the use of semioccluding chitosan membranes in microfluidic MFCs to separate electrodes with submillimeter spacing. The study is aided by computational electrochemical fluid dynamics and electrochemical impedance spectroscopy. Furthermore, the bioelectrocatalytic performance of the system was investigated with a pure culture Geobacter sulferreduces electroactive biofilm $(\mathrm{EAB})$ and results were compared to a membraneless microfluidic MFC with a larger electrode separation.

\section{Materials and methods}

\section{$\underline{\text { Device fabrication }}$}

Microfluidic moulds were made by photolithography. The photomask motif was designed and printed by computer-aided design software (DraftSightTM, Dassault Systèmes, France) and a photoplotter (FPS25000, Fortex Engineering Ltd., UK). Dry photoresist films (SY300 film, Fortex Engineering Ltd., UK) with a final thickness of $150 \mu \mathrm{m}$ were attached to a $75 \times 50 \times 1$ mm glass slide (12-550 C, Fisher Scientific, Canada) using a dry film laminator (FL-0304-01, Fortex Engineering Ltd., UK). The photomask was combined against the laminated photoresist surface and exposured to UV light (AY-315, Fortex Engineering Ltd., UK). The unexposed photoresist was dissolved by the developer and rinse solutions (SY300 Developer/Rinse, Fortex Engineering Ltd., UK). Two graphite electrodes (Isomolded Graphite Plate, Graphitestore.com Inc., USA) were covered with a protective laminate and placed onto the mould in a side-by-side arrangement such that their overlap with the channel would result in an exposure area of $3 \times 10 \mathrm{~mm}$. Then a mixture of PDMS and a cross-linker was poured over the mould, and the assembly was cured at $70{ }^{\circ} \mathrm{C}$ overnight. Four inlets and three outlets were 
punched into the device to admit fluid conduits. Two glass plates were plasma bonded (PCD001, Harrick Plasma, USA) for 90 seconds at 600 mTorr to the device. One to seal the channels (on the bottom side) and the other was placed on the outer surface (top side) to prevent oxygen penetration through the air-permeable PDMS material. Inlets and outlets were connected to connective tubing (PFA tube 1/16", Hamilton Inc., Canada) that were made gas-impermeable using a layer of gas-impermeable tape (Loctite 249 Anaerobic Blue Threadlocker Tape, Medium Strength, Henkel Corp., Canada), and an epoxy coating (LOCTITE Epoxy, HenKel Corp, Canada). The same epoxy was applied to all remaining exposed PDMS. Gas tight glass syringes (DGA glass syringe, $50 \mathrm{~mL}$, Sigma-Aldrich, Canada) were connected to the tubing and operated at selected flow rates by syringe pumps (PhD 2000, Harvard Apparatus, MA). More details on the design and final membrane MFC device are shown in Figure 1. The schematics of the membrane and membraneless MFC studied this work are shown side-by-side in Supporting Information, Figure S1. The smooth transition from PDMS to electrodes was critical for predictable flow patterns required during synthesis of well-formed membranes (Supporting Information, Figure S2).

(a)

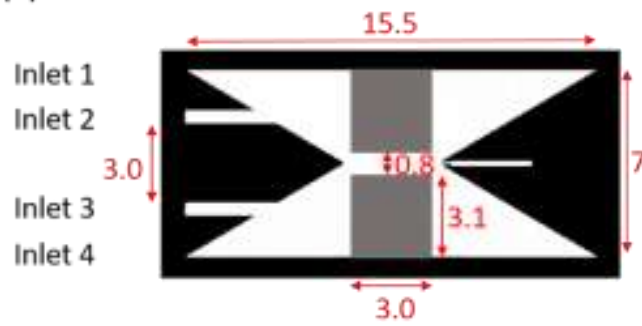

(c)

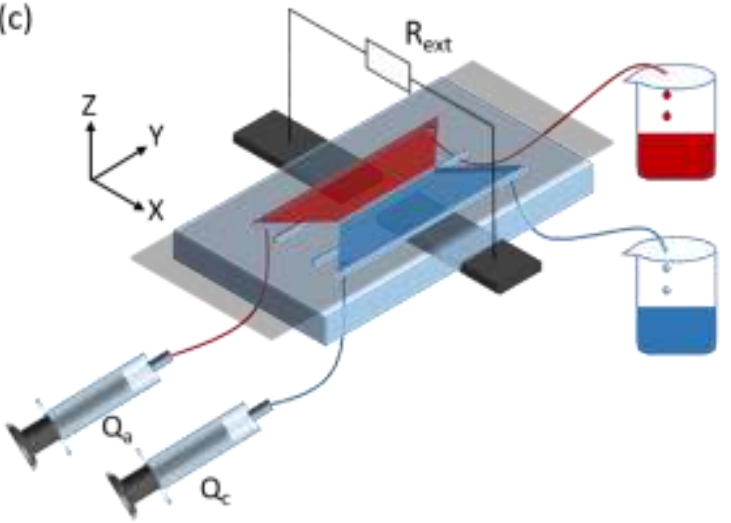

(b)

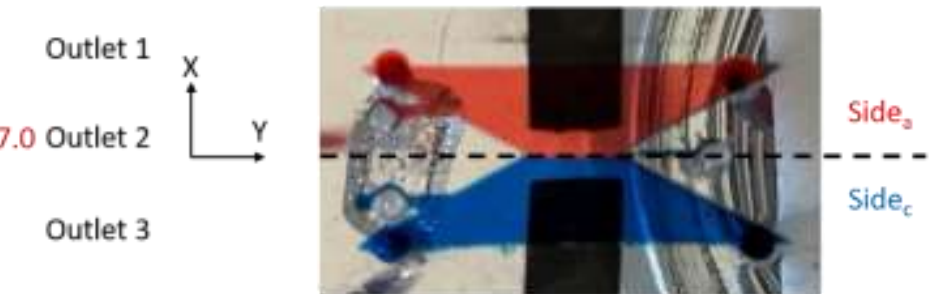

(d)

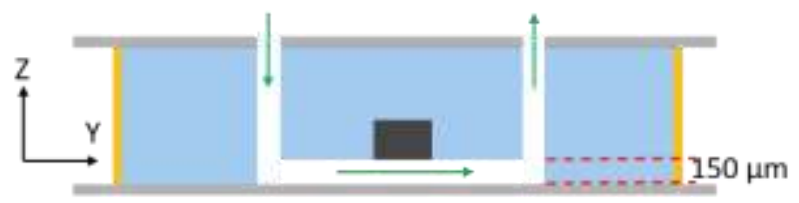


Figure 1. Experimental setup. (a) The designed mask pattern for a membrane microfluidic electrochemical flow cell shows four inlets (Inlets 1 to 4 ) and three outlets (Outlets 1 to 3) with dimensions indicated. (b) The experimental device prepared in this work, with a co-flow interface with contrast enhanced by colour dyes. The anode and cathode side are indicated as Side $_{\mathrm{a}}$ and Side , respectively. (c) Isometric view of the membrane MFC showing fluidic connections to anolyte and catholyte, red and blue, respectively, and the electrical connection of the anode and cathode through the external resistor, $\mathrm{R}_{\mathrm{ext}}$. All units are in millimeters $(\mathrm{mm})$. (d) Cross-section schematic (y-z plane) showing $150 \mu \mathrm{m}$ channel height, and device fabrication materials: PDMS (blue), graphite (black), glass cover slip and outer layer sealing protection (grey), epoxy walls (yellow). Outlet 2 is not shown as it is blocked after membrane formation. Only 1 inlet and 1 outlet are shown because they have the same y-position as the other(s). The green arrows show the flow direction.

\section{Chitosan membrane synthesis}

The chitosan solution was prepared by adding $0.05 \mathrm{~g}$ of chitosan (medium molecular weight, Sigma-Aldrich, Canada) into $9 \mathrm{~mL}$ deionized water with final concentration of $5.5 \mathrm{mg} \mathrm{mL}-1$. Around $30 \mu \mathrm{L}$ of $1 \mathrm{M} \mathrm{HCl}$ solution was added to maintain $\mathrm{pH} 2$ and stirred at room temperature for two hours. The solution was filtered with a $0.2 \mu \mathrm{m}$ syringe filter before use. The phosphatebuffered saline solution (10 mM phosphate buffer, $2.7 \mathrm{mM} \mathrm{KCl}$ and $137 \mathrm{mM} \mathrm{NaCl}, \mathrm{pH} 7.4$ ) was introduced as sheath flow into Inlets 1 and 4 (Figure 1a). Both $\mathrm{NaOH}$ and $\mathrm{HCl}$ solutions were connected to Inlet 2 via a switching valve. The chitosan solution flowed on-chip via a connection to Inlet 3. Initially, $\mathrm{HCl}$ and chitosan solutions flowed on-chip ( $\mathrm{QHCl}_{\mathrm{HCl}}=1.0 \mathrm{~mL} \mathrm{~h}^{-1}$, $\mathrm{Q}_{\text {chitosan= }}=0.8 \mathrm{~mL} \mathrm{~h}^{-1}$ ) and were surrounded by a sheath flow of PBS solution (both buffer flow

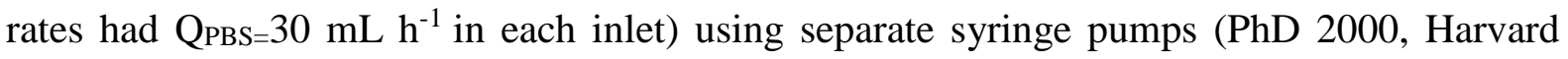
Apparatus, MA). A calming period of 10 minutes was implemented to allow the laminar co- 
flow between all 4 streams to become steady with electrodes being contacted by only the PBS buffer (Supporting Information, Figure S3). Before switching Inlet 2 to $\mathrm{NaOH}$, we ensured that the sheath flow completely covered the electrodes, preventing their contact by membrane reagent streams during synthesis. Then $\mathrm{HCl}$ solution was changed to $\mathrm{NaOH}$ solution by a switching valve, while maintaining the same flow rate $\left(\mathrm{Q}_{\mathrm{NaOH}}=1.0 \mathrm{~mL} \mathrm{~h}{ }^{-1}\right)$. After approximately 25 mins, the chitosan membrane was fully formed, reaching its final thickness of 20 to $50 \mu \mathrm{m}$. Then, pumping was stopped for $\mathrm{NaOH}$ and chitosan solutions through Inlets 2 and 3, while the PBS buffer continued to flow through Inlets 1 and 4. The PBS washed out any unreacted precursor molecules from the channel, membrane, and any other surfaces of the microfluidic channel. The selected flow rates enabled the electrodes to be contacted by only PBS during the entire synthesis process.

\section{Microscopy}

Transmission microscopy was conducted on an inverted microscope (IX73, Olympus, Canada) with 10x objective to monitor the position and thickness of the membrane during its synthesis. Confocal laser scanning microscopy (CLSM, FV1200, Olympus, Canada) was used to characterize the membrane size in three dimensions using the $\mathrm{z}$-scan option with a $100 \times$ objective, with a vertical resolution of $1.5 \mu \mathrm{m}$.

\section{Bacteria preparation and inoculation}

A green fluorescence protein (GFP) expressing G. sulfurreducens was used for these investigations. The strain was gifted by Prof. Derek Lovely (University of Massachusetts, Amherst, USA) and is the same as has been used previously. ${ }^{22,23}$ All air-sensitive operations were performed in an anaerobic glove box $\left(10 \% \mathrm{H}_{2}, 10 \% \mathrm{CO}_{2}\right.$, and $\left.80 \% \mathrm{~N}_{2}\right)$. G. sulfurreducens were thawed from ceramic beads from $-80{ }^{\circ} \mathrm{C}$ and subcultured in a nutrient medium with the 
addition of $40 \mathrm{mM}$ fumarate to provide a usable electron acceptor for planktonic bacteria. The base nutrient medium (without fumerate) contained the following components in 1 litre of distilled water: $\mathrm{CH}_{3} \mathrm{COONa}(10 \mathrm{mM}) ; \mathrm{KH}_{2} \mathrm{PO}_{4}(0.42 \mathrm{~g}) ; \mathrm{K}_{2} \mathrm{HPO}_{4}(0.22 \mathrm{~g}) ; \mathrm{NH}_{4} \mathrm{Cl}(0.2 \mathrm{~g}) ; \mathrm{KCl}$ (0.38 g); $\mathrm{NaCl}(0.36 \mathrm{~g}) ; \mathrm{CaCl}_{2} \cdot 2 \mathrm{H}_{2} \mathrm{O}(0.04 \mathrm{~g}) ; \mathrm{MgSO}_{4} \cdot 2 \mathrm{H}_{2} \mathrm{O}(0.1 \mathrm{~g}) ; \mathrm{NaHCO}_{3}(1.8 \mathrm{~g}) ;$ a trace mineral supplement (10 mL) (ATCC® MD-TMS $\left.{ }^{\mathrm{TM}}\right)$; a vitamin supplement $(10 \mathrm{~mL})(\mathrm{ATCC} \AA$ MD-TMS $\left.{ }^{\mathrm{TM}}\right)$, cysteine $(1 \mathrm{mM})$, spectinomycin $(150 \mathrm{mg})$. The nutrient medium was purified using a $2 \mu \mathrm{m}$ sterilized syringe filter before use. ${ }^{6,24}$

The microfluidic device was inoculated by injecting a fumarate-containing planktonic $G$. sulfurreducens inoculum into side $\mathrm{a}_{\mathrm{a}}$ using a $10 \mathrm{~mL}$ syringe at a flow rate of $\mathrm{Q}_{\mathrm{a}}=0.5 \mathrm{~mL} \mathrm{~h}^{-1}$. Ferricyanide $(30 \mathrm{mM}$, in a $\mathrm{pH} 7.0$ sodium phosphate buffer) flowed through the cathode compartment at flow rate $\mathrm{Q}_{\mathrm{c}}=0.5 \mathrm{~mL} \mathrm{~h}^{-1}$. Inoculation lasted for 24 hours under the total flow rate of $\mathrm{Q}_{\mathrm{T}}=\mathrm{Q}_{\mathrm{a}}+\mathrm{Q}_{\mathrm{c}}=1.0 \mathrm{~mL} \mathrm{~h}^{-1}$. After inoculation, a sterile nutrient medium without fumarate was supplied to the channel at the same flow rate. This eliminated electron transfer to the solution, thus promoting G. sulfurreducens growth on the anode.

Based on concentrations of each ionic species, the ionic strengths were calculated to be 69.9 $\mathrm{mM}$ and $331.3 \mathrm{mM}$ for the acetate growth medium (anolyte), and ferricyanide solution in PBS (catholyte), respectively.

\section{Polarization tests and calculation of current and power density}

Following the switch to a fumarate-free nutrient medium, EABs growth on the anode was monitored. Using a commercial potentiostat (Parstat MC 200, Princeton Applied Research, Oak Ridge, USA) to constinously record the voltage drop across the external resistor, $\mathrm{R}_{\text {ext. }}$ The same setup was used to periodically performe a polarization test, from which polarization and power density curves were obtained. Polarization tests were achieved using a switched resistor approach (in the range $\mathrm{R}_{\mathrm{ext}}=100$ to $\mathrm{R}_{\mathrm{ext}}=4 \mathrm{k} \Omega$ ), utilizing a potentiostat connected directly across 
the anode/cathode. The changing voltage (V) across the external resistor after switching from OCV was monitored as a function of time and could be converted to current density $(\overline{\mathrm{I}})$ using Ohm's law and by accounting for the anode area $\left(\mathrm{A}_{\text {anode }}\right)$ :

$$
\overline{\mathrm{I}}=\frac{\mathrm{V}}{\mathrm{R}_{\mathrm{ext}} \mathrm{A}_{\text {anode }}}
$$

Polarization curves were then obtained by plotting V vs $\bar{I}$ at each $R_{\text {ext }}$ value tested during the polarization measurement. during the Power density curves were obtained by Equation 2:

$$
\overline{\mathrm{P}}=\overline{\mathrm{I}} \mathrm{V}
$$

\section{Electrochemical impedance spectroscopy}

Electrochemical impedance spectroscopy (EIS) was used to determine the electrochemical properties of graphite electrodes and solution resistance before and after membrane synthesis. Electrochemical impedance spectroscopy measurements were conducted in the frequency range of $100 \mathrm{MHz}$ to $1 \mathrm{~Hz}$ (10 points per decade) with a sinusoidal perturbation amplitude of $10 \mathrm{mV}$ (Squidstat Plus, Admiral Instruments, LLC, Tempe, USA). Nyquist plots were fitted with an equivalence circuit (Supporting Information, Figure S4) using EC Lab V11.36 to support characterization of solution resistance and charge transfer resistance. In addition to two graphite electrode devices shown in Figure 1, devices containing reference electrodes were fabricated for a series of membrane tests in different configurations. Titanium electrodes were used as pseudo-reference electrodes. These were created from Titanium wires (Titanium wire $0.25 \mathrm{~mm}, 99.7 \%$ trace metals basis, Sigma-Aldrich, Canada), which were flatted by a hydraulic press (Model M, Carver 4339, Carver Inc., USA). Measurements were conducted in a $10 \mathrm{mM}$ phosphate buffer before and after membrane preparation. The device has two sides, the anode side $\left(\right.$ Side $\left._{\mathrm{a}}\right)$ and the cathode side $\left(\right.$ Side $\left._{\mathrm{c}}\right)$ for each electrode investigation.

\section{$\underline{\text { Acetate conversion efficiency and other flow-based figures of merit. }}$}


The acetate conversion efficiency $\left(\varepsilon_{\mathrm{Ac}}\right)$ is represented as the percentage of the acetate concentration that becomes oxidized:

$$
\varepsilon_{\mathrm{Ac}}=\frac{\left([\mathrm{Ac}]_{\mathrm{i}}-[\mathrm{Ac}]_{\mathrm{f}}\right)}{[\mathrm{Ac}]_{\mathrm{i}}} \times 100 \%
$$

where the initial acetate concentration at the inlet is given as $[\mathrm{Ac}]_{\mathrm{i}}\left(\mathrm{mol} \mathrm{L} \mathrm{L}^{-1}\right)$ and the final acetate concentration after oxidation is given as $[\mathrm{Ac}]_{\mathrm{f}}$. The acetate turnover rate, $\frac{\mathrm{dmol}_{\mathrm{Ac}}}{\mathrm{dt}}(\mathrm{mol} \mathrm{s}-$ $\left.{ }^{1}\right)$, is the consumption of acetate per unit time, which can be calculated from the current: ${ }^{25}$

$$
\frac{\mathrm{dmol}_{\mathrm{Ac}}}{\mathrm{dt}}=\frac{\mathrm{I}}{8 \mathrm{~F}}
$$

where $\mathrm{F}$ is Faraday's constant, $\mathrm{F}=9.6485 \times 10^{4} \mathrm{C} \mathrm{mol}^{-1}$, and 8 is the electron transfer number for acetate oxidation reaction on anode. The final acetate concentration can be calculated from the acetate turnover rate, and acetate flow rate, $\mathrm{Q}_{\mathrm{a}}\left(\mathrm{L} \mathrm{s}^{-1}\right):{ }^{26}$

$$
[\mathrm{Ac}]_{\mathrm{f}}=[\mathrm{Ac}]_{\mathrm{i}}-\frac{\mathrm{dmol}_{\mathrm{Ac}}}{\mathrm{dt}} / \mathrm{Q}_{\mathrm{a}}
$$

Thus, the acetate conversion efficiency is a unitless value that can be calculated from the following equation:

$$
\varepsilon_{\mathrm{Ac}}=\frac{\mathrm{I}}{8 \mathrm{~F} \cdot \mathrm{Q} \cdot[\mathrm{Ac}]_{\mathrm{i}}} \times 100 \%
$$

To convert between volumetric flow rates, $\mathrm{Q}\left(\mathrm{mL} \mathrm{h}^{-1}\right)$, and linear flow velocity, $v\left(\mathrm{~m} \mathrm{~min}^{-1}\right)$, we used the following equation,

$$
v=\frac{\mathrm{Q}}{\mathrm{hw} 30}
$$

Where $\mathrm{h}$ and $\mathrm{w}$ are the channel height and width (in mm each).

\section{Computer simulations}

The concentration profiles studied in this work were simulated via software (COMSOL Multiphysics 5.4, COMSOL, Inc., USA), using physics for secondary current distribution, transport of diluted species, and laminar flow. The electrolyte composition was assumed to remain constant due to continuous flow of the nutrient medium containing supporting 
electrolytes at a high ionic strength. Thus, secondary current distribution was used to describe the electrochemical reactions as a function of the overpotential. In addition, the commonly used Butler-Volmer equation that describes the relation between current density and overpotential at electrode/electrolyte interface was expanded to include the dependence of electrode reaction kinetics on species concentrations. The secondary current distribution was combined with mass transport including diffusion, migration, and convection by the Poisson-Nernst-Planck equation to describe concentration dependent current distributions. ${ }^{27}$ The boundary conditions in simulations were obtained from experimental current measurements due to its direct relation to the redox reaction rate. The maximum current density obtained in experiment of $3.5 \mathrm{~A}$ was used as the boundary condition applied to the anode as an upper limit on acetate assumption and oxidation by-product outputs. The ions involved in the simulated electrode reactions (Eqns. 8, 9) included acetate, protons, bicarbonate, ferrocyanide, and ferricyanide via electrode reactions which were coupled to mass transport equations. Mass transport included convection based on an inlet velocity $(v)$, diffusion (based on diffusivity for acetate, $D_{A c^{-}}=10.89 \times 10^{-10} \mathrm{~m}^{2}$ $\mathrm{s}^{-1}$, ferricyanide, $\mathrm{D}_{\mathrm{Fe}(\mathrm{CN})_{6}^{3-}}=8.96 \times 10^{-10} \mathrm{~m}^{2} \mathrm{~s}^{-1}$, ferrocyanide, $\mathrm{D}_{\mathrm{Fe}(\mathrm{CN})_{6}^{4-}}=7.35 \times 10^{-10} \mathrm{~m}^{2} \mathrm{~s}^{-1}$, protons $\mathrm{D}_{\mathrm{H}^{+}}=93.11 \times 10^{-10} \mathrm{~m}^{2} \mathrm{~s}^{-1}$, and bicarbonate, $\left.\mathrm{D}_{\mathrm{HCO}_{3}^{-}}=11.9 \times 10^{-10} \mathrm{~m}^{2} \mathrm{~s}^{-1}\right),{ }^{28}$ and migration in electric field. The reaction equations for acetate oxidation on the anode and ferricyanide reduction on cathode are shown below:

$$
\begin{gathered}
\mathrm{CH}_{3} \mathrm{COO}^{-}+4 \mathrm{H}_{2} \mathrm{O} \rightleftharpoons 2 \mathrm{HCO}_{3}^{-}+9 \mathrm{H}^{+}+8 \mathrm{e}^{-} \\
\mathrm{Fe}(\mathrm{CN})_{6}^{3-}+\mathrm{e}^{-} \rightleftharpoons \mathrm{Fe}(\mathrm{CN})_{6}^{4-}
\end{gathered}
$$

\section{Results and discussion}

\section{Membrane synthesis}

The membrane was synthesized as explained in the experimental section. Following the methodology for membrane synthesis outlined in the experimental section, we observed a thin 
chitosan membrane was synthesized between two electrodes following the introduction of the chitosan and $\mathrm{NaOH}$ solutions. Depending on flow conditions during their synthesis, membranes widths of less than $100 \mu \mathrm{m}$ (Figures 2a-d) and heights that were equal or less than that of the channel. CLSM was used to accurately characterize the sizes of two membranes formed in separate devices with different electrode spacing. In each case the membrane synthesis was stopped before the full vertical height of the channel was occupied. As observed previously the membrane grew downwards from the top of the device (PDMS side) which we believe is due to the membrane having a lower density than the pre-curses solutions. ${ }^{20}$ This resulted in a $5 \mu \mathrm{m}$ gap between the membrane and the bottom glass surface, whereas the membrane was well-connected to the PDMS/electrode side of the device as shown schematically in Figure 2. We exploited this small gap on the glass side of the device (opposite from the electrodes) to provide adequate connection between the anolyte and catholyte solutions for ion transport, in lieu of optimized transport properties through the membrane. In addition to reducing the internal resistance of the cell, we anticipated that this would provide a "controlled cross-over region" where differences in pressure could be alleviated without breaking the membrane. But, due to the gap position being opposite to the electrode layer, moderate amounts of cross-over could be tolerated without contamination of the liquid layer in contact with the electrodes. 
(a)

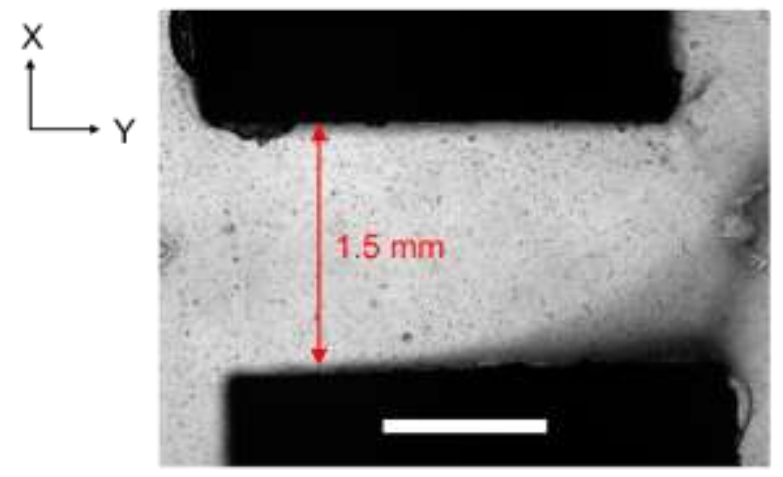

(c)

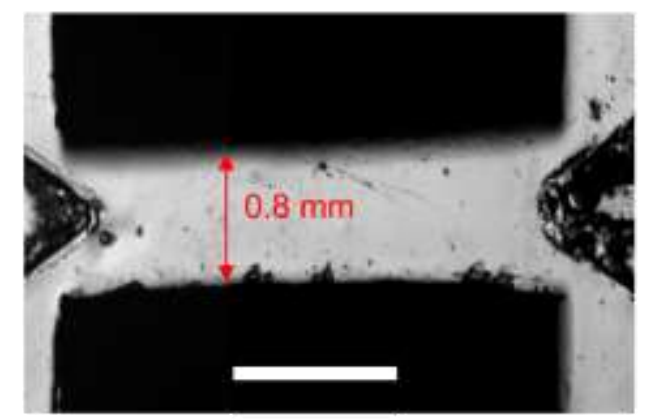

(e) (b)

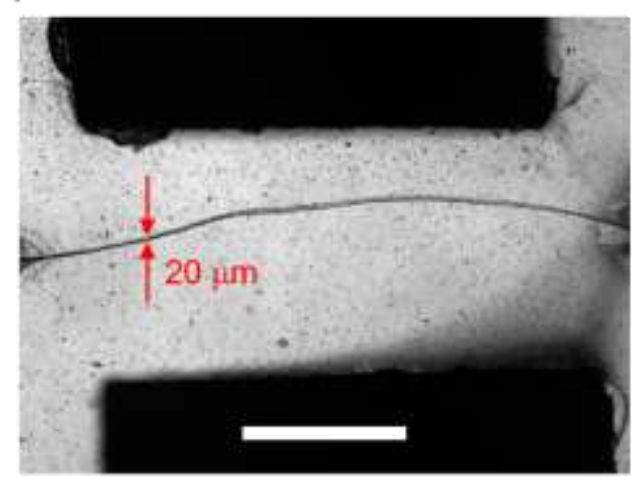

(d)

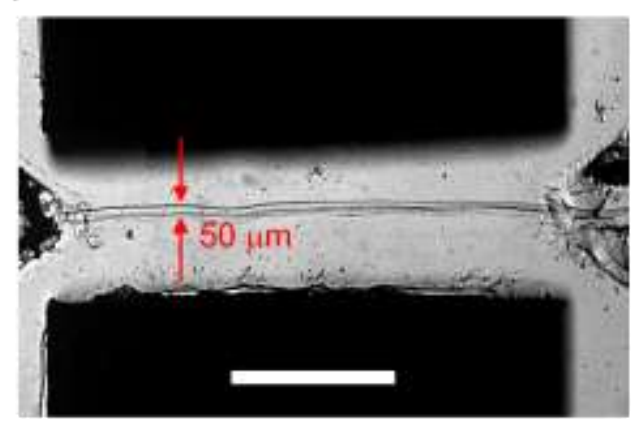

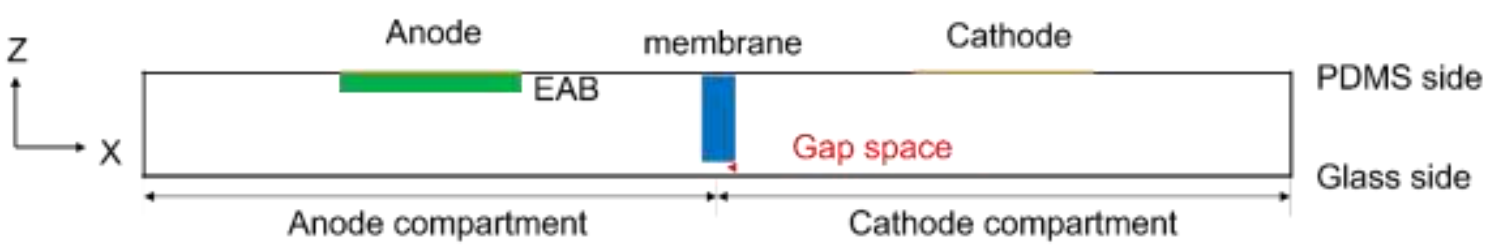

Figure 2. Micrograph of the region between graphite anode and cathode in the $x-y$ plane (obtained using $2 \times$ microscope objective). A close up of device with $1.5 \mathrm{~mm}$ electrode spacing is shown before (a) and after (b) the synthesis of a $20 \mu \mathrm{m}$-wide membrane (with sheath flow on each side being $Q_{P B S}=30 \mathrm{~mL} \mathrm{~h}^{-1}$ ). A second device with $0.8 \mathrm{~mm}$ electrode spacing is shown before (c) and after (d) the synthesis of a $50 \mu \mathrm{m}$-wide membrane (with sheath flow on each side being $\mathrm{Q}_{\mathrm{PBS}}=40 \mathrm{~mL} \mathrm{~h}^{-1}$ ). In both cases the flow $\mathrm{Q}_{\text {chitosan }}=1 \mathrm{~mL} \mathrm{~h}^{-1}$ and $\mathrm{Q}_{\mathrm{NaOH}}=2 \mathrm{~mL} \mathrm{~h}^{-1}$. The scale bar in all cases represents $1 \mathrm{~mm}$ in all images. Flow was from left to right. (e) A schematic of the device at the $\mathrm{x}-\mathrm{z}$ plane. The membrane (blue) extends from attachment point at the PDMS/electrode surface, leaving a small gap at the glass surface. 
Before and after the chitosan membrane formation inside the microfluidic MFC, Nyquist plots were obtained from the EIS measurement with the microchannel filled with $100 \mathrm{mM}$ phosphate buffer at $\mathrm{Q}_{\mathrm{T}}=1 \mathrm{~mL} \mathrm{~h}^{-1}$. To determine the resistance of the membrane and if its synthesis affected electrode performance, EIS was conducted. Solution/membrane resistance and charge transfer resistances $\left(\mathrm{R}_{\mathrm{s} / \mathrm{m}}, \mathrm{R}_{\mathrm{ct}}\right.$, respectively) were quantitatively determined using an electrical equivalent circuit. To accomplish this, two different electrode configurations were selected: (i) $\mathrm{WE}_{\mathrm{a}}, \mathrm{RE}_{\mathrm{a}}$, and $\mathrm{CE}_{\mathrm{c}}$, and (ii) $\mathrm{WE}_{\mathrm{c}}, \mathrm{RE}_{\mathrm{c}}$ and $\mathrm{CE}_{\mathrm{a}}$, as shown in insets of Figures $3 \mathrm{a}$ and $3 \mathrm{~b}$, respectively. Under both setups the Nyquist plots contained a semicircle feature at high frequencies, which is indicative of a charge transfer process on the working electrode (Figure 3a, 3b). The $x$-intercept at high frequency gives the solution/membrane resistance. Extending toward lower frequencies in the Nyquist plot is a capacitive linear segment. Before membrane formation, $R_{s / m}=1998 \pm 8.51 \Omega$ as measured using electrode configuration (i) and $R_{s / m}=1857 \pm$ $13 \Omega$ as measured using electrode configuration (ii). The difference between the two measured $\mathrm{R}_{\mathrm{s} / \mathrm{m}}$ values could be related to differences in inter-electrode distances or in electrode dimensions between the two electrode configurations. After membrane formation, the solution/membrane resistances increased to $\mathrm{R}_{\mathrm{s} / \mathrm{m}}=2060 \pm 14.47 \Omega$ and to $\mathrm{R}_{\mathrm{s} / \mathrm{m}}=1932 \pm 8.11 \Omega$ using electrode configuration (i) and (ii), respectively. Following membrane synthesis, the average increase in $R_{s / m}$ was $68.5 \Omega$. The increased resistance was statistically significant (compared to the fitting uncertainty) and is attributed to the membrane. Analysis of charge transfer resistance on the graphite electrode on Side $_{a}$ (using electrode configuration (i)) was $\mathrm{R}_{\mathrm{ct}, \mathrm{a}}=833.61 \pm 3.38 \Omega$ and $\mathrm{R}_{\mathrm{ct}, \mathrm{a}}=866.55 \pm 60.59 \Omega$ before and after membrane synthesis, respectively. Analysis of charge transfer resistance on the graphite electrode on $\operatorname{Side}_{\mathrm{c}}$ (Using electrode configuration (ii)) was $\mathrm{R}_{\mathrm{ct}, \mathrm{c}}=593 \pm 87.76 \Omega$ and $624 \pm 5.11 \Omega$ before and after membrane synthesis, respectively. The differences in $R_{\mathrm{ct}}$ were not statistically significant (compared to the fitting uncertainly), so we conclude that there were no residual effects of the 
membrane synthesis on the electrochemical properties of either graphite electrode. We attribute this to the PBS sheath flow which protected the electrodes from contacting precursor liquids during membrane synthesis. Experiments which did not contain a sheath flow resulted in $\mathrm{R}_{\mathrm{ct}}$ values that were significantly changed after membrane synthesis (data not shown).

(a)
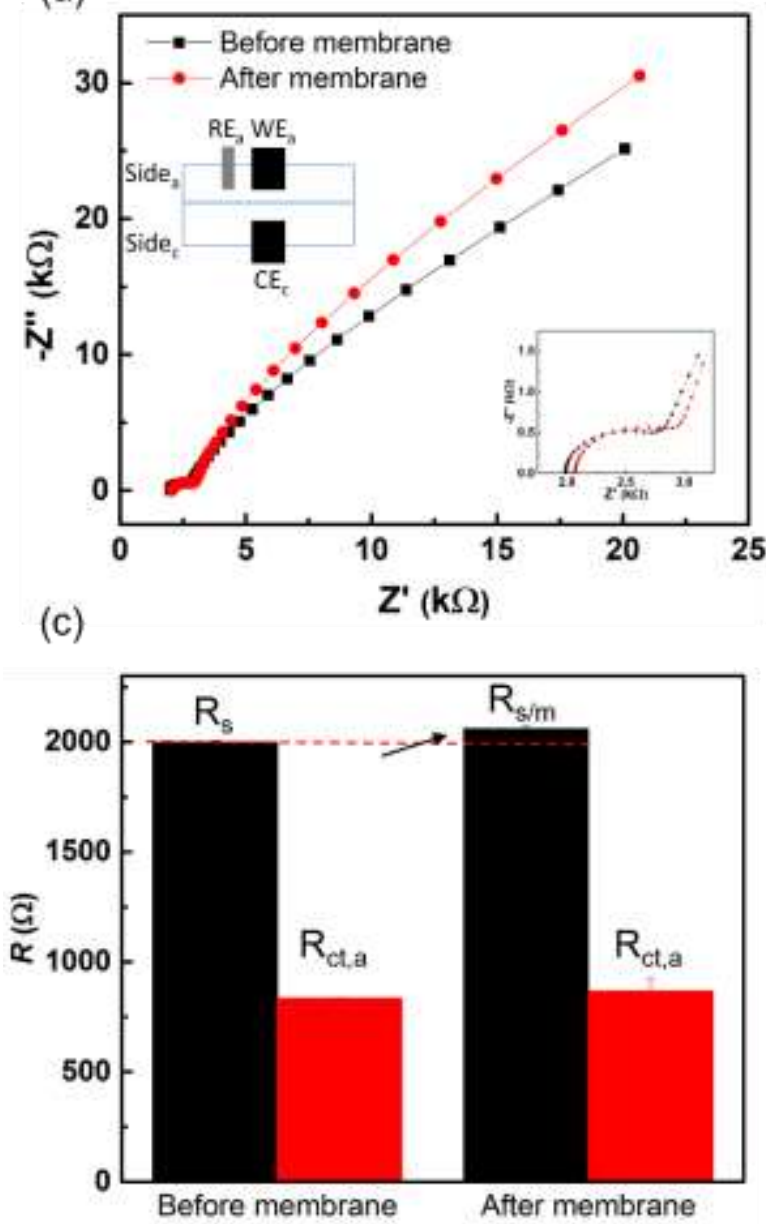

(b)

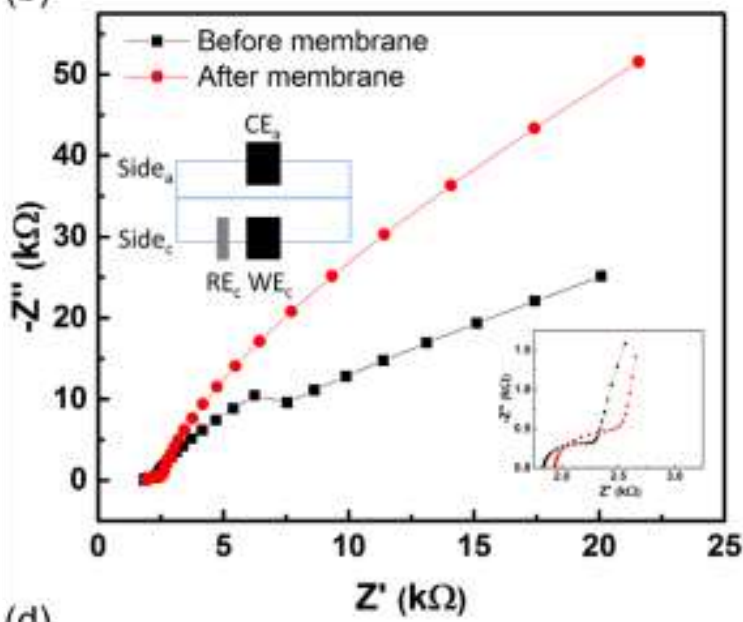

(d)

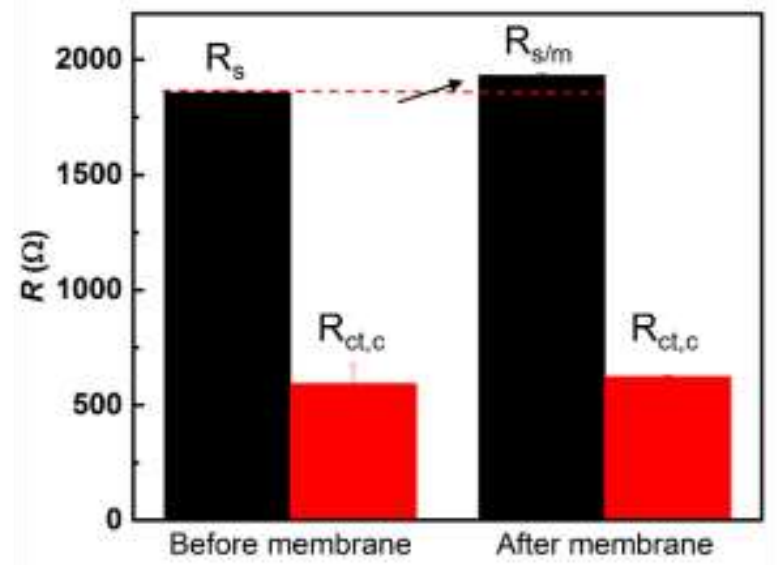

Figure 3. Results from electrochemical impedance spectroscopy before and after membrane synthesis. Nyquist plots from electrochemical impedance spectroscopy using electrode configurations (i) and (ii) in (a) and (b), respectively. Electrodes included pseudo reference electrode (RE), working electrode (WE), and counter electrode (CE). Subscripts indicate anode (a) or cathode (c) sides. Inset figures show a close up of Nyquist plot at the high frequency side. Fitting results for solution resistance $\left(R_{s}\right)$ before membrane and solution/membrane $\left(R_{s / m}\right)$ 
after membrane and charge transfer resistance $\left(\mathrm{R}_{\mathrm{ct}}\right)$ before and after membrane synthesis from (a) and (b) are shown in (c) and (d), respectively. Error bars in (c) and (d) report on uncertainty in the fitting procedure. In all cases, the reported uncertainty, arose from the fitting procedure.

Previously, we studied solution crossover in the standard membraneless microfluidic MFC as a function of electrode distance. ${ }^{14}$ In those simulations the anolyte and catholyte flow rates were balanced. In the following work, we simulated three different flow conditions on both the standard $6 \mathrm{~mm}$ membraneless MFC design (Figure 4a) and the present membrane MFC (Figure 4b): (i) $\mathrm{Q}_{\mathrm{a}}=\mathrm{Q}_{\mathrm{c}}=0.5 \mathrm{~mL} \mathrm{~h}^{-1}$ (balanced flow), (ii) $\mathrm{Q}_{\mathrm{a}}=0.7 \mathrm{~mL} \mathrm{~h}^{-1}, \mathrm{Q}_{\mathrm{c}}=0.3 \mathrm{~mL} \mathrm{~h}^{-1}$, and (iii) $\mathrm{Q}_{\mathrm{a}}=0.3$ $\mathrm{mL} \mathrm{h}^{-1}, \mathrm{Q}_{\mathrm{c}}=0.7 \mathrm{~mL} \mathrm{~h}^{-1}$. For the membraneless MFC under balanced flow $\left(\mathrm{Q}_{\mathrm{a}}=\mathrm{Q}_{\mathrm{c}}\right)$, the simulated acetate concentration profile was as expected (Figure 4a (i)). Under imbalanced flow where $\mathrm{Q}_{\mathrm{a}}>\mathrm{Q}_{\mathrm{c}}$, the acetate solution was shifted to cathode compartment (Figure 4a (ii)). When $\mathrm{Q}_{\mathrm{c}}>$ $\mathrm{Q}_{\mathrm{a}}$, ferricyanide solution shifts to the anode compartment (Figure $4 \mathrm{a}$ (iii)). The same behavior was observed in the experiments by monitoring the change in position of the faint yellow ferricyanide stream (data not shown). A quantitative test of the cross-over was obtained by measuring the solution resistance from EIS measurements due to different in ionic strength between anolyte and catholyte (Figure S5). The differences in the simulated acetate concentration profiles for the membrane device with the membrane in place were imperceptible at three flow conditions (Figures $4 \mathrm{~b}$ (i-iii)). A Nyquist plot from EIS measurements during imbalanced flow in the membrane device did not show a significant difference in the fitted solution resistance, conforming that the membrane prevent any perceptible solution cross-over (data not shown). On the contrary, imbalanced flow in the same submillimeter MFC without the membrane installed affects on the co-flow interface position much like for the membraneless device, but the contamination of the opposite electrode is more severe due to the closer electrode spacing. (Figures 4c (i-iii)). 
(a)

(i)

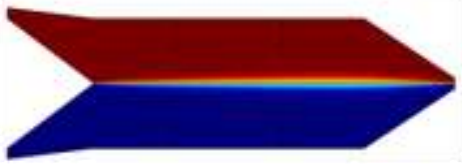

(ii)

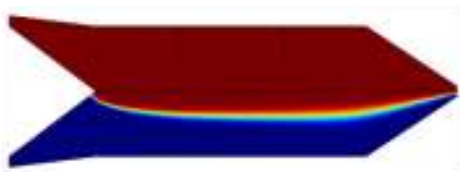

(iii)

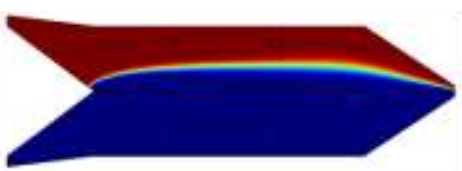

(b)

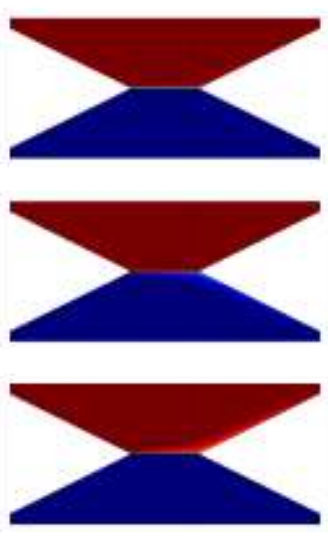

(c)
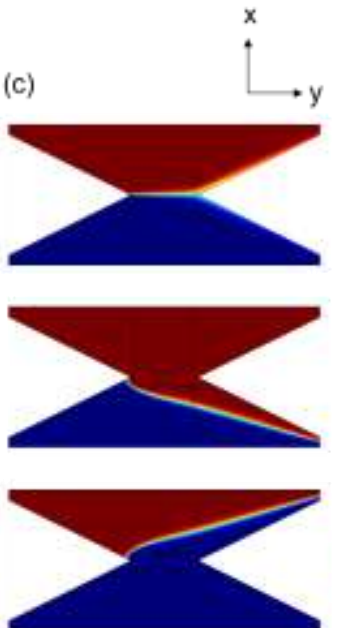

Figure 4. Simulated acetate concentration profiles for the standard $6 \mathrm{~mm}$ membraneless MFC (a), $0.8 \mathrm{~mm}$ electrode spacing membrane (b) and membraneless (c) MFC under three flow conditions: (i) $\mathrm{Q}_{\mathrm{a}}=\mathrm{Q}_{\mathrm{c}}=0.5 \mathrm{~mL} \mathrm{~h}^{-1}$, (ii) $\mathrm{Q}_{\mathrm{a}}=0.7 \mathrm{~mL} \mathrm{~h}^{-1}, \mathrm{Q}_{c}=0.3 \mathrm{~mL} \mathrm{~h}^{-1}$, and (iii) $\mathrm{Q}_{\mathrm{a}}=0.3 \mathrm{~mL} \mathrm{~h}^{-1}$, $\mathrm{Q}_{\mathrm{c}}=0.7 \mathrm{~mL} \mathrm{~h}^{-1}$.

The contour line of $2 \mathrm{mM}$ acetate for membrane submillimeter MFCs was plotted with an imbalanced flow (ii) (Figure S6a). The contour line showed a less shift at the PDMS side due to the block of the membrane. While the contour line shift was more obvious on the glass side with $5 \mu \mathrm{m}$ gap. The same trends was observed with contour line of $6 \mathrm{mM}$ ferricyanide at an imbalanced flow (iii) (Figure S6b).

A major hurdle for microfluidic MFCs is to improve their operational times. For example, one study using the same $6 \mathrm{~mm}$ electrode separation membraneless MFCs shown here achieve 6month operational time, ${ }^{14}$ but in another study using the same design, we had to solve a problem of a developing power overshoot. ${ }^{15}$ Each new design modification should be evalued from the perspective of operational longevity. With this goal in mind, we next verify the effect of the acetate oxidation products (Eqn. 8) on their interaction with the membrane because the membrane can be dissolved in solutions with $\mathrm{pH}$ lower than $5 .^{20}$ To accomplish this, we 
simulated the proton concentration profile in the vicinity of the membrane (Figures 5a and 5b). A similar plot of the $\mathrm{HCO}_{3}^{-}$ion concentration was shown in Figures $5 \mathrm{c}$ and $5 \mathrm{~d}$. The protons produced by the acetate oxidation reaction has a maximum concentration of $10.8 \mathrm{mM}$ over the anode, whereas its maximum concentration on membrane was $6.8 \mathrm{mM}$. However, the nutrient medium has a calculated buffer capacity of $12.9 \mathrm{mM} \mathrm{pH}^{-1}$, which limited the solution acidification at the membrane surface to only $\mathrm{pH}$ values between 6.8 to 6.4 (Supporting Information, Section S7). The almost unchanged $\mathrm{pH}$ indicates that the acetate reaction byproducts do not affect the membrane integrity. This is supported by experiment, which shows that the membrane is stable over the entire operational time of the MFC. Further studies on the MFCs under different electrode separation distances were also simulated and the readers refer to Figure S7 and S8.

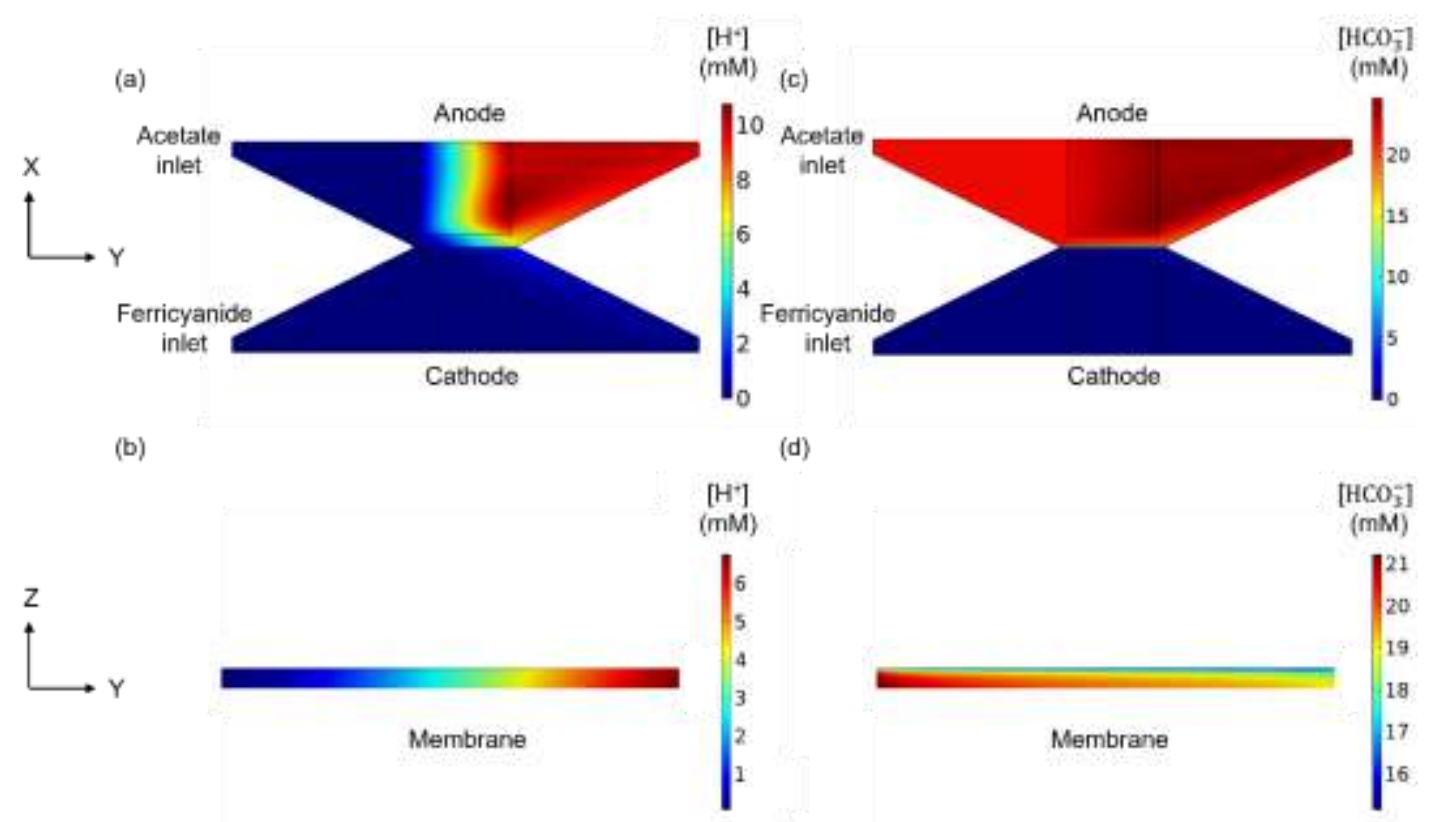

Figure 5. The proton and bicarbonate ion concentration profiles in solution (a), (c) and zoomed views on membrane position (b) and (d). The conditions including the maximum current density of $\overline{\mathrm{I}}_{\max }=3.54 \mathrm{~A} \mathrm{~m}^{-2}$, total flow rate of $\mathrm{Q}_{\mathrm{T}}=0.1 \mathrm{~mL} \mathrm{~h}^{-1}, 10 \mathrm{mM}$ acetate, and $30 \mathrm{mM}$ ferricyanide at inlets were applied. 


\section{MFC start up and growth curves}

After synthesis of the chitosan membrane, the microfluidic MFC was inoculated with $G$. sulfurreducens for 24 hours with anolyte (inoculant) and co-flowing catholyte at a balanced flow rate such that flow velocity was $0.01 \mathrm{~m} \mathrm{~min}^{-1}$. The initial external resistor was set to 100 $\mathrm{k} \Omega$. After inoculation, a switching valve admitted a sterile stream of acetate anolyte, and a typical G. sulfurreducens growth curve was obtained (Figure 6). A $10 \mathrm{~h}$ lag phase was observed during which $G$. sulfurreducens were switching to a sessile phenotype in order to switch to an anode respiration mode in the absences of dissolved fumarate. After that, G. sulfurreducens began to grow exponentially with changing growth rates of $\mathrm{k}_{\mathrm{I}}=0.09 \mathrm{~h}^{-1}, \mathrm{k}_{\mathrm{II}}=0.04 \mathrm{~h}^{-1}, \mathrm{k}_{\mathrm{III}}=0.02$ $\mathrm{h}^{-1}$ during the first 40 hours. The corresponding doubling times (calculated as $1 / \mathrm{k}_{\mathrm{I}}, 1 / \mathrm{k}_{\mathrm{II}}$ and $1 / \mathrm{k}_{\text {III }}$ ) are longer than optimal observed values of approximately 6 hours. This is likely due to sub-optional grow temperature at $21^{\circ} \mathrm{C}$. After around 60 hours of growth, the voltage became steady. The time reach to maturity is short compared to larger static MFCs, and demonstrates another advantage of microfluidic MFCs.

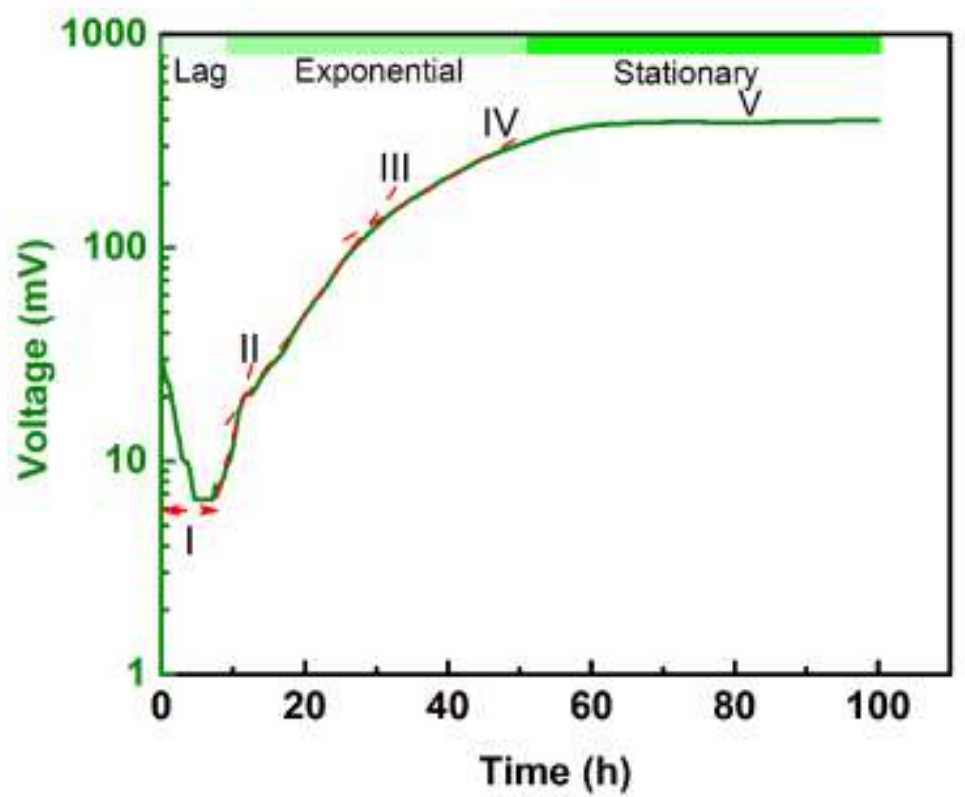

Figure 6. Microfluidic MFC start-up. Growth curve of G. sulfurreducens across an external resistor $(100 \mathrm{k} \Omega)$ with $[\mathrm{Ac}]=10 \mathrm{mM}$ in the anode compartment and $[\mathrm{Fe}]=30 \mathrm{mM}$ in the cathode compartment. The total flow rate was $\mathrm{Q}_{\mathrm{T}}=0.1 \mathrm{~mL} \mathrm{~h}^{-1}$. Data are plotted in log-scale in y-axis to 
identify five growth stages: (I) lag phase, (II)-(IV) three exponential growth phases with respective exponential growth constants with $\mathrm{k}_{\mathrm{I}}=0.09 \mathrm{~h}^{-1}, \mathrm{k}_{\mathrm{II}}=0.04 \mathrm{~h}^{-1}, \mathrm{k}_{\mathrm{III}}=0.02 \mathrm{~h}^{-1}$ and (V) stationary phase.

To ensure the outputs were stable in the long term, we waited one week, then we conducted polarization tests under a constant flow rate of $\mathrm{Q}_{\mathrm{T}}=0.1 \mathrm{~mL} \mathrm{~h}^{-1}$. The polarization test was conducted by a switched resistor technique where different external resistors were applied after the voltage was settled under OCV conditions (Figure S9). This approach prevents any acclimation to the decreasing external resistor values during the polarization test. Therefore the results are expected to produce conservative values, compared o the long-term operation at any single $\mathrm{R}_{\text {ext. }}{ }^{15}$ We note that the voltages always achieved stable values before voltage readings were obtained which indicates low internal resistance. ${ }^{15}$ From these results, power density $(\overline{\mathrm{P}})$ and current density $(\overline{\mathrm{I}})$ for each $\mathrm{R}_{\mathrm{ext}}$ were calculated, and power density and polarization curves were generated (Figure 7). The maximum power density of $\overline{\mathrm{P}}_{\mathrm{max}}=546 \mathrm{~mW} \mathrm{~m} \mathrm{~m}^{-2}$ was obtained with an external resistor of $\mathrm{R}_{\mathrm{ext}}=10 \mathrm{k} \Omega$ applied, whereas, in separate measurements on a membraneless MFC with $6 \mathrm{~mm}$ electrode spacing, the maximum power density was only $\overline{\mathrm{P}}_{\text {max }}=376 \mathrm{~mW} \mathrm{~m} \mathrm{~m}^{-2}$ with $\mathrm{R}_{\mathrm{ext}}=25 \mathrm{k} \Omega$. The maximum current density of $\overline{\mathrm{I}}_{\mathrm{max}}=3.54 \mathrm{~A} \mathrm{~m}^{-2}$ was

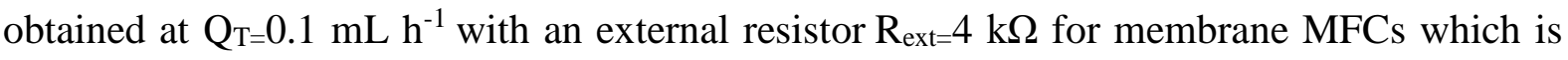
higher than $0.91 \mathrm{~A} \mathrm{~m}^{-2}$ obtained from membraneless microfluidic MFCs at $\mathrm{Q}_{\mathrm{T}}=1.0 \mathrm{~mL} \mathrm{~h}^{-1}$ with $\mathrm{R}_{\mathrm{ext}}=10 \mathrm{k} \Omega$. As a measure of the internal resistance, $10 \mathrm{k} \Omega$ is indeed low compared to the other microfluidic MFC used in this study $(25 \mathrm{k} \Omega)$. 


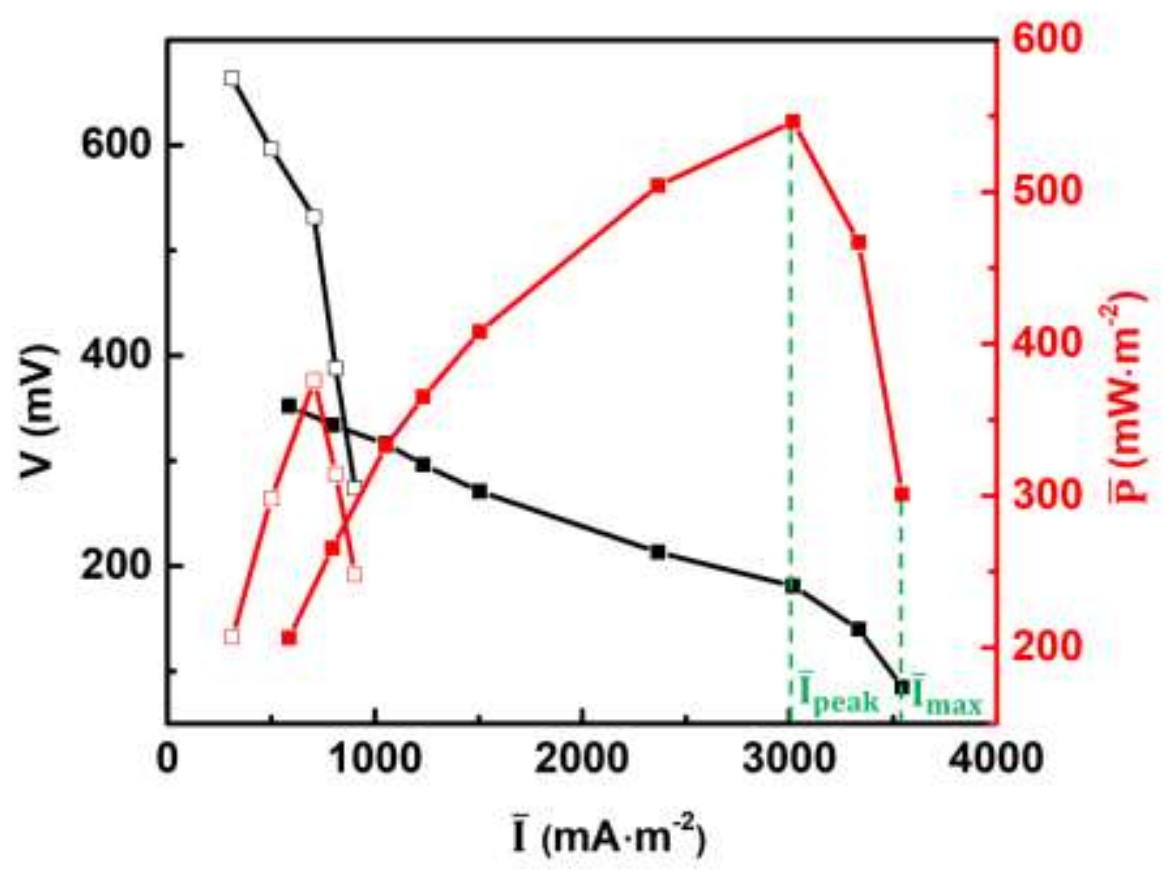

Figure 7. The power density curve (red) and polarization curve (black) for membrane (solid square) and membraneless (hollow square). The membrane MFCs is at a total flow rate of $\mathrm{Q}_{\mathrm{T}}=0.1 \mathrm{~mL} \mathrm{~h}^{-1}$ with external resistors switched from OCV to $100,70,50,40,30,15,10,7,4$ $\mathrm{k} \Omega$. The membraneless MFC is at a total flow rate of $\mathrm{Q}_{\mathrm{T}}=1 \mathrm{~mL} \mathrm{~h}^{-1}$ with external resistors switched from $\mathrm{OCV}$ to $70,40,25,16,10 \mathrm{k} \Omega$. Current density at maximum power and maximum current density for the membrane MFC are marked $\overline{\mathrm{I}}_{\text {peak }}$, and $\overline{\mathrm{I}}_{\text {max }}$, respectively.

We transformed maximum current densities from Figure 7 into maximum currents based on electrode areas and combined them with the corresponding flow rates. Then using Eqn. 6, we calculated the acetate conversion efficiency for the two microfluidic MFCs used in this work. For the membrane microfluidic MFC, the acetate conversion efficiency was calculated to be $19.81 \%$ at the maximum current density of $\overline{\mathrm{I}}_{\max }=3.54 \mathrm{~A} \mathrm{~m}^{-2}, \mathrm{Q}_{\mathrm{T}}=0.1 \mathrm{~mL} \mathrm{~h}^{-1}$, and initial acetate concentration of $10 \mathrm{mM}$. For the membraneless microfluidic MFC, the acetate conversion efficiency was only $2.5 \%$ at the maximum current density of $\bar{I}_{\max }=0.91 \mathrm{~A} \mathrm{~m}^{-2}, \mathrm{Q}_{\mathrm{T}}=1 \mathrm{~mL} \mathrm{~h}^{-1}$ and initial acetate concentration of $10 \mathrm{mM}$. Despite having much lower contact time of $\mathrm{t}_{\mathrm{c}}=37.8$ 
s (Eqn. 10) for the membrane MFC, its acetate conversion efficiency of $19.8 \%$ was 8 times higher compared the membraneless MFC which had a $t_{c}=60 \mathrm{~s}$ and a conversion efficiency of only $2.5 \%$ for the membraneless MFC.

$$
\mathrm{t}_{\mathrm{c}}=0.06 \frac{\mathrm{l}}{\mathrm{v}}
$$

where $\mathrm{t}_{\mathrm{c}}(\mathrm{s})$ is the contact time, $l(\mathrm{~mm})$ is the electrode length exposed to the solution.

This is an improvement of 8 times which we credit to two benefits of closely spaced electrodes, being (i) higher current density and (ii) less opportunity for the liquid cross-over between the electrode compartments.

To test the effect of flow on membrane MFC performance, different total flow rate (and corresponding flow velocity) between $0.1 \mathrm{~mL} \mathrm{~h}^{-1}\left(0.01 \mathrm{~m} \mathrm{~min}^{-1}\right)$ to $20 \mathrm{~mL} \mathrm{~h}^{-1}\left(0.95 \mathrm{~m} \mathrm{~min}^{-1}\right)$ were tested while voltage measurements were made across an external resistor of $R_{\text {ext }}=10 \mathrm{k} \Omega$. Here we discuss the percentage power increase, $\Delta \mathrm{P}(\%)$, as a function of flow rate over the minimum flow rate $\left(\mathrm{Q}_{\mathrm{T}}=0.1 \mathrm{~mL} \mathrm{~h}^{-1}\right)$. This is shown in Figure $8 \mathrm{a}$ with flow rate transformed to flow velocity. A maximum percentage power increase was obtained from $\mathrm{Q}_{\mathrm{T}}=10 \mathrm{~mL} \mathrm{~h} \mathrm{~h}^{-1}$ but did not significantly increase above $10 \mathrm{~mL} \mathrm{~h}^{-1}$. This supports a previous conclusion that previously observed reduction in power density at high flow rates may be the result of electrode contamination due to flow-based instabilities that cause solution cross-over. ${ }^{14}$ While power did not significantly increase with flow over $10 \mathrm{~mL} \mathrm{~h}^{-1}$, the membrane did not fail at any attempted flow rates (up to $140 \mathrm{~mL} \mathrm{~h}^{-1}$ ). It should also be noted that the membrane enabled very slow flow rates, while membraneless MFCs were not stable due to pump instability at these flow rates (data not shown). The power increases versus flow velocity for membrane MFCs and membraneless MFCs were compared in Figure 8b. The results from membrane MFCs showed that at smaller $\mathrm{Q}_{\mathrm{T}}$ values, ranging from $0.2 \mathrm{~mL} \mathrm{~h}^{-1}$ to $0.5 \mathrm{~mL} \mathrm{~h}^{-1}$, percentage power increase improved from $20.5 \%$ to $24.4 \%$. After that, percentage power increase grew slow slowly, from $\mathrm{Q}_{\mathrm{T}}=1 \mathrm{~mL} \mathrm{~h}^{-1}$ to $\mathrm{Q}_{\mathrm{T}}=5 \mathrm{~mL} \mathrm{~h}^{-1}$. When the flow rate reached $10 \mathrm{~mL} \mathrm{~h}^{-1}$, the percentage power 
increase became stable at $29.4 \%$. Further increasing $\mathrm{Q}_{\mathrm{T}}$ to $20 \mathrm{~mL} \mathrm{~h}^{-1}$ did not affect the percentage power increase. To facilitate a comparison with a membraneless MFC, which has different channel dimensions, we calculate the flow velocity, ranging from 0.02 to $1.22 \mathrm{~m} \mathrm{~min}^{-}$ 1. Compared with the membraneless MFC, the percentage power increase for the membrane MFC increased faster at lower flow rate and resulted in a maximum $\Delta \mathrm{P}$ of $5 \%$ higher than for the membraneless MFC.

(a)

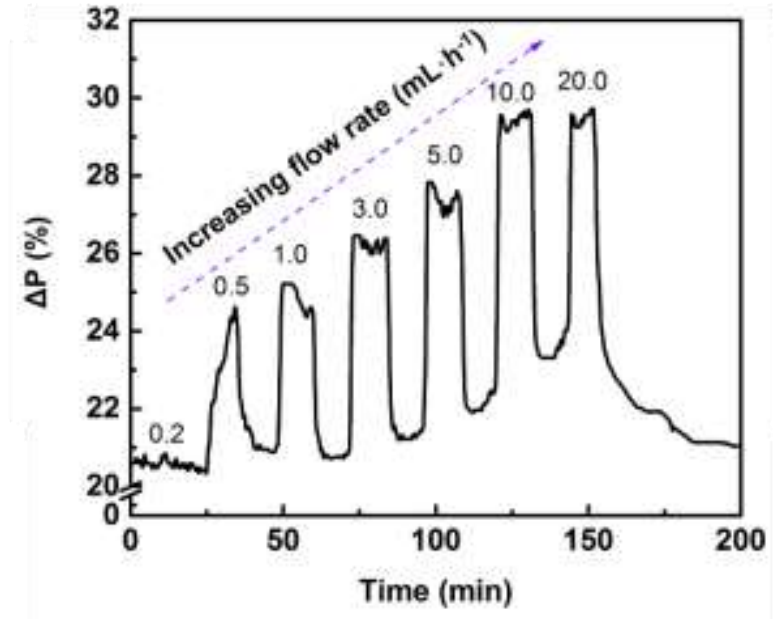

(b)

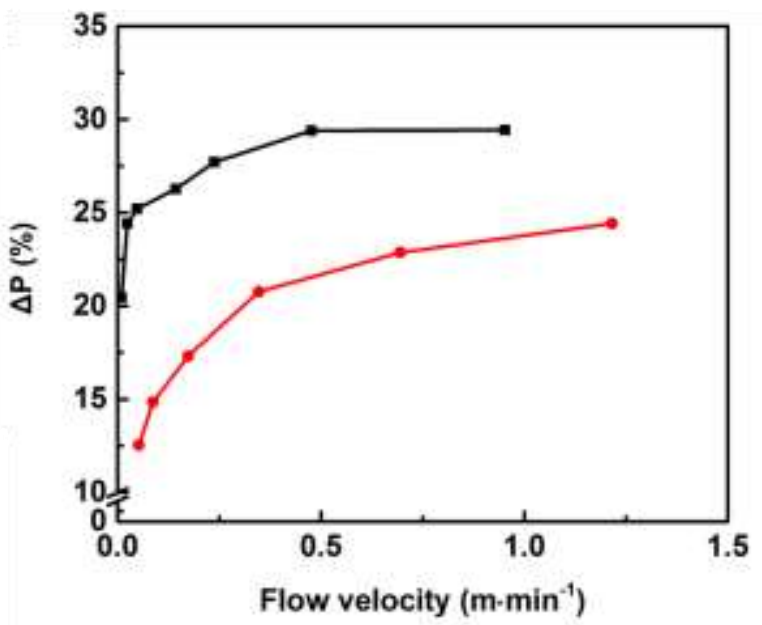

Figure 8. (a) Results the corresponding percentage power increase, $\Delta \mathrm{P}(\%)$, with time by applying flow rates ranging from $\mathrm{Q}_{\mathrm{T}}=0.2 \mathrm{~mL} \mathrm{~h}^{-1}$ to $\mathrm{Q}_{\mathrm{T}}=20 \mathrm{~mL} \mathrm{~h}^{-1}$ on microfluidic membrane MFCs under $10 \mathrm{k} \Omega$ resistors when exposure to a baseline flow rate of $\mathrm{Q}_{\mathrm{T}=0.1 \mathrm{~mL} \mathrm{~h}}{ }^{-1}$. (b) Average percentage power increase in (a) with flow velocities corresponding to the volumetric flow rates in (a) for the membrane (black) and membraneless (red) MFCs with 6 mm electrode spacing.

\section{Conclusion}

In this work, we demonstrate microfluidic MFCs as a new application for microscale chitosan membranes. The successful fabricating of a microfluidic MFC with a chitosan separation membrane supported a reduction in inter-electrode spacing down to $0.8 \mathrm{~mm}$. From the 
experimental results, it showed that reduced electrode spacing resulted in an increase in power output of $546 \mathrm{~mW} \mathrm{~m}^{-2}$ at a flow rate of $\mathrm{Q}_{\mathrm{T}}=0.1 \mathrm{~mL} \mathrm{~h}^{-1}$ which increased by almost $30 \%$ at $\mathrm{Q}_{\mathrm{T}=10}$ $\mathrm{mL} \mathrm{h}^{-1}$. This compares favorably for a lower membraneless MFC with an inter electrode separation of $6 \mathrm{~mm}$ which produced a maximum power density of $376 \mathrm{~mW} \mathrm{~m}^{-2}$ flowing at a comparable flow velocity (resulting from volumetric flow rate of $\mathrm{Q}_{\mathrm{T}}=1 \mathrm{~mL} \mathrm{~h}^{-1}$ ). That is, the membrane MFC showed an improved power density of $45 \%$ compared to the membraneless device. Perhaps most important was the maximum current value of $3.54 \mathrm{~A} \mathrm{~m}^{-2}$, which, to our knowledge is the highest reported value for any microfluidic MFC. As a result of the high current and reduced ability for acetate solution to by-pass the anode in the membrane set-up, the unoptimized acetate conversion efficiencies were nearly $20 \%$, which was 7 times higher than for the $6 \mathrm{~mm}$ membraneless MFC, despite the very small anode size, and corresponding contact time with the acetate solution. Further studies should be conducted to optimize ion transfer, perhaps by controlling membrane porosity ${ }^{29}$ or by implementing nano hybrid membranes, ${ }^{20}$ or by direct modification of the chitosan amide groups. ${ }^{30,31}$ Further power, elongated electrodes for better contact time and improved acetate conversion efficiency.

\section{Conflict of Interest}

The authors declare no conflict of interest.

\section{Acknowledgements}

The authors acknowledge financial support from the China Scholarship Council (CSC) program (ID 201704910951), Sentinelle Nord, and the Natural Sciences and Engineering Research Council of Canada. 


\section{References}

1. Logan, B. E., Simultaneous wastewater treatment and biological electricity generation. Water Sci Technol 2005, 52 (1-2), 31-37.

2. Logan, B. E.; Hamelers, B.; Rozendal, R. A.; Schrorder, U.; Keller, J.; Freguia, S.; Aelterman, P.; Verstraete, W.; Rabaey, K., Microbial fuel cells: Methodology and technology. Environ Sci Technol 2006, 40 (17), 5181-5192.

3. Logan, B. E.; Wallack, M. J.; Kim, K.-Y.; He, W.; Feng, Y.; Saikaly, P. E., Assessment of Microbial Fuel Cell Configurations and Power Densities. Environmental Science \& Technology Letters 2015, 2 (8), 206-214.

4. Wang, H.; Park, J. D.; Ren, Z. J., Practical energy harvesting for microbial fuel cells: a review. Environ Sci Technol 2015, 49 (6), 3267-3277.

5. Hong Liu, R. R., Bruce E. Logan, Production of Electricity during Wastewater Treatment Using a Single Chamber Microbial Fuel Cell. Environ. Sci. Technol 2004, 38, 2281-2285.

6. Abbaszadeh Amirdehi, M.; Saem, S.; Zarabadi, M. P.; Moran-Mirabal, J. M.; Greener, J., Microstructured Anodes by Surface Wrinkling for Studies of Direct Electron Transfer Biofilms in Microbial Fuel Cells. Advanced Materials Interfaces 2018, 5 (13). 
7. Jung Rae Kim, S. C., Sang-Eun Oh, Bruce E. Logan, Power Generation Using Different Cation, Anion, and Ultrafiltration Membranes in Microbial Fuel Cells. Environ. Sci. Technol 2007, 41, 1004-1009.

8. Rossi, R.; Logan, B. E., Using an anion exchange membrane for effective hydroxide ion transport enables high power densities in microbial fuel cells. Chemical Engineering Journal 2021, 422, 1-8.

9. Rossi, R.; Baek, G.; Saikaly, P. E.; Logan, B. E., Continuous Flow Microbial Flow Cell with an Anion Exchange Membrane for Treating Low Conductivity and Poorly Buffered Wastewater. ACS Sustainable Chemistry \& Engineering 2021, 9 (7), 2946-2954.

10. Kook, L.; Quemener, E. D.; Bakonyi, P.; Zitka, J.; Trably, E.; Toth, G.; Pavlovec, L.; Pientka, Z.; Bernet, N.; Belafi-Bako, K.; Nemestothy, N., Behavior of two-chamber microbial electrochemical systems started-up with different ion-exchange membrane separators. Bioresour Technol 2019, 278, 279-286.

11. Asensio, Y.; Fernandez-Marchante, C. M.; Lobato, J.; Cañizares, P.; Rodrigo, M. A., Influence of the ion-exchange membrane on the performance of double-compartment microbial fuel cells. Journal of Electroanalytical Chemistry 2018, 808, 427-432.

12. Rossi, R.; Wang, X.; Logan, B. E., High performance flow through microbial fuel cells with anion exchange membrane. Journal of Power Sources 2020, 475.

13. Oliot, M.; Etcheverry, L.; Mosdale, A.; Basseguy, R.; Délia, M. L.; Bergel, A., Separator electrode assembly (SEA) with 3-dimensional bioanode and removable air-cathode boosts microbial fuel cell performance. Journal of Power Sources 2017, 356, 389-399.

14. Amirdehi, M. A.; Khodaparastasgarabad, N.; Landari, H.; Zarabadi, M. P.; Miled, A.; Greener, J., A High - Performance Membraneless Microfluidic Microbial Fuel Cell for Stable, Long - Term Benchtop Operation Under Strong Flow. ChemElectroChem 2020, 7 (10), 2227-2235.

15. Amirdehi, M. A.; Gong, L.; Khodaparastasgarabad, N.; Sonawane, J. M.; Logan, B. E.; Greener, J., Hydrodynamic interventions and measurement protocols to quantify and mitigate power overshoot in microbial fuel cells using microfluidics. Electrochimica Acta 2022, 405 .

16. Choi, S.; Lee, H. S.; Yang, Y.; Parameswaran, P.; Torres, C. I.; Rittmann, B. E.; Chae, J., A muL-scale micromachined microbial fuel cell having high power density. Lab Chip 2011, $11(6), 1110-1117$. 
17. Hideaki Hisamoto, Y. S., Kenji Uchiyama, Manabu Tokeshi, Yoshikuni Kikutani, Akihide Hibara, Takehiko Kitamori, Chemicofunctional Membrane for Integrated Chemical Processes on a Microchip. Anal. Chem 2003, 75, 350-354.

18. Luo, X.; Berlin, D. L.; Betz, J.; Payne, G. F.; Bentley, W. E.; Rubloff, G. W., In situ generation of $\mathrm{pH}$ gradients in microfluidic devices for biofabrication of freestanding, semipermeable chitosan membranes. Lab Chip 2010, 10 (1), 59-65.

19. Ly, K. L.; Hu, P.; Pham, L. H. P.; Luo, X., Flow-assembled chitosan membranes in microfluidics: recent advances and applications. J Mater Chem B 2021, 9 (15), 3258-3283.

20. Jia, N.; Rosella, E.; Juere, E.; Pouliot, R.; Kleitz, F.; Greener, J., A microfluidic approach to micromembrane synthesis for complex release profiles of nanocarriers. Lab Chip $\mathbf{2 0 2 0}$, 20 (6), 1066-1071.

21. Rosella, E.; Jia, N.; Mantovani, D.; Greener, J., A microfluidic approach for development of hybrid collagen-chitosan extracellular matrix-like membranes for on-chip cell cultures. Journal of Materials Science \& Technology 2021, 63, 54-61.

22. Coppi, M. V.; Leang, C.; Sandler, S. J.; Lovley, D. R., Development of a genetic system for Geobacter sulfurreducens. Appl Environ Microbiol 2001, 67 (7), 3180-3187.

23. Tang, H. Y.; Yang, C.; Ueki, T.; Pittman, C. C.; Xu, D.; Woodard, T. L.; Holmes, D. E.; Gu, T.; Wang, F.; Lovley, D. R., Stainless steel corrosion via direct iron-to-microbe electron transfer by Geobacter species. ISME J 2021, 15 (10), 3084-3093.

24. Zarabadi, M. P.; Charette, S. J.; Greener, J., Flow-Based Deacidification of Geobacter sulfurreducens Biofilms Depends on Nutrient Conditions: a Microfluidic Bioelectrochemical Study. ChemElectroChem 2018, 5 (23), 3645-3653.

25. Zarabadi, M. P.; Couture, M.; Charette, S. J.; Greener, J., A Generalized Kinetic Framework Applied to Whole - Cell Bioelectrocatalysis in Bioflow Reactors Clarifies Performance Enhancements for Geobacter Sulfurreducens Biofilms. ChemElectroChem 2019, 6 (10), 2715-2718.

26. Zarabadi, M. P.; Charette, S. J.; Greener, J., Toggling Geobacter sulfurreducens metabolic state reveals hidden behaviour and expanded applicability to sustainable energy applications. Sustainable Energy \& Fuels 2019, 3 (9), 2211-2217.

27. John Newman, K. E. T.-A., Electrochemical systems. third ed.; John Wiley \& Sons, Inc., : United states, 2004.

28. Buffle, J.; Zhang, Z.; Startchev, K. J. E. s.; technology, Metal flux and dynamic speciation at (bio) interfaces. Part I: Critical evaluation and compilation of physicochemical 
parameters for complexes with simple ligands and fulvic/humic substances. 2007, 41 (22), 7609-7620.

29. Tang, C.; Zhang, Q.; Wang, K.; Fu, Q.; Zhang, C., Water transport behavior of chitosan porous membranes containing multi-walled carbon nanotubes (MWNTs). Journal of Membrane Science 2009, 337 (1-2), 240-247.

30. Malhotra, M.; Lane, C.; Tomaro-Duchesneau, C.; Saha, S.; Prakash, S., A novel method for synthesizing PEGylated chitosan nanoparticles: strategy, preparation, and in vitro analysis. Int J Nanomedicine 2011, 6, 485-494.

31. Zhuang, P. Y.; Li, Y. L.; Fan, L.; Lin, J.; Hu, Q. L., Modification of chitosan membrane with poly(vinyl alcohol) and biocompatibility evaluation. Int J Biol Macromol 2012, 50 (3), 658-663. 